\title{
Alcohol, women, and the young: the same old problem?
}

\author{
RICHARD SMITH
}

Those who treat alcoholics have over the last decade observed an increase in the number of women and young people in their units. ${ }^{1}$ This has led to the idea that not only is the prevalence of all alcohol problems increasing but that the increase among women and the young may be proportionately steeper. But, as Roberta Ferrence has pointed out, "it is a well known psychological phenomenon that people tend to overestimate the proportion of persons in a group who belong to a visible minority, particularly when their presence is unexpected.". So are there more women and young people with alcohol problems, and if there are why should this be so ? Moreover, should these groups be placed in a special category when strategies for prevention and treatment are considered?

\section{Women and alcohol}

Just as more men in Britain have problems with alcohol compared with 10 years ago, so do more women. Whether, however, the proportionate increase in women is steeper than in men is hard to answer. The epidemiology of alcohol and alcoholism is, as explained before (3 October, p 895), a difficult art, but Shaw has produced evidence from Britain suggesting that alcohol problems are increasing disproportionately among women. ${ }^{3}$

Firstly, convictions for drunkenness have risen faster for women than men. In 1967, 71167 men and 4377 women were convicted, meaning that women committed $5.8 \%$ of all offences. By 1976 convictions for women had risen to 8642 and they committed $8.6 \%$ of all offences. Similarly, in 1968 women committed $1.6^{\circ} \%$ of the 18384 drunken driving offences compared in 1977 with $3.1 \%$ of the 45369 such offences. But the figures for women remain small compared with those for men, and the changes may not necessarily mean that more women are becoming drunk: they may, for example, just mean that policemen are becoming more likely to arrest women.

Shaw also notes that the number of women admitted to hospital with alcohol problems rose from 1043 in 1964 to 3028 in 1975, and that over that time the ratio of men to women changed from $3 \cdot 9: 1$ to $2 \cdot 7: 1$. Again, this might be something to do with changing admission policies, but Shaw also presents some necessarily rather loose evidence that the ratio of men to women who present to Alcoholics Anonymous or councils on alcoholism has also fallen. Finally, he shows that mortality among women from cirrhosis and other problems attributable to alcohol has also risen, although the ratio of men to women has changed little.

This amounts to convincing evidence that alcohol problems among women are increasing but not that the increase is pro-

British Medical Journal, London WC1H 9JR

RICHARD SMITH, BSC, MB, assistant editor portionately greater among women than men. Ferrence reviewed many studies searching for evidence to support this hypothesis, which is called "the convergence hypothesis." From these studies of change in consumption, mortality, morbidity, and drinking offences she concluded that "there was no clear evidence that rates of problem drinking for women and men have converged." She was reviewing mainly American data, of course, and the British experience may be different, as Shaw suggests. So good evidence exists that women, in common with men, are experiencing more alcohol problems, but the evidence that women's problems are increasing faster than men's is less convincing.

\section{Why are women experiencing more alcohol problems?}

Nobody can provide a complete explanation of why the prevalence of alcohol problems is increasing in most Western countries. The increase in consumption is obviously vitally important, but why do so many people drink more than is reasonable? When considering why problems are increasing among women there is a temptation to resort to elaborate but unsubstantiated theories: everybody seems to have an axe to grind.

What is certain is that some of the social and economic factors that have been found to be important in determining how much people drink as a whole (3 October, p 895) are especially important with women. For instance, not only have women's average incomes risen but they have risen proportionately faster than men's. ${ }^{3}$ Also, between 1968 and 1977 the number of women working rose from 8814000 to 10066000 , whereas the number of men working fell. Thus as the real price of alcohol has fallen the disposable income of women has risen fast, and this is an important factor in determining alcohol consumption. Direct evidence that women's alcohol consumption has risen is hard to come by, but over the past two decades the biggest increases in consumption have been in drinks like sherry, vermouth, table wine, and vodka-drinks more associated with women-rather than in beer, which is traditionally drunk by men. Individual manufacturers of these drinks also have evidence from surveys that it is women who are buying more sherry, vermouth, table wine, and the like. ${ }^{3}$

A whole pot pourri of social factors have made it easier for women to use alcohol. Working, for instance, not only produces money for buying alcohol but also time and opportunity for drinking. Many women work in jobs particularly associated with alcohol problems: in 1978 there were over twice as many women as men working in pubs. ${ }^{3}$ There are now more outlets where women can buy and consume alcohol: supermarkets have dramatically increased their sales of alcohol, and wine bars have appeared and prospered. Some suggest that the success of wine bars depends on the fact that it is acceptable for women to drink alone in them. Furthermore, advertisers and producers have recognised the hugeness of the potential market and directed more of their advertising specifically at women. 
In addition to these economic and social factors there are undoubtedly important psychological factors. Some talk of the increasing stress on women because of the dual pressures of career and home and general confusion over their roles in society, while others talk of women "paying the price of liberation" with increased alcohol problems. Ferrence makes an interesting point when she reminds us how women have before been subjected to "scare tactics" in times of social change: for instance, suffragettes were told that their reproductive systems would wither, and more recently juvenile delinquency and mental breakdown have been blamed on working mothers." Maybe much of the noise about women and alcohol has the same origin.

\section{Reproduction and alcohol}

The tendency to "blame" women for their drinking is nowhere more apparent than with alcohol and pregnancy. The idea that alcohol may interfere with reproduction has a long history, ${ }^{4}$ but only in the late 1960 s did researchers begin to suggest that a particular syndrome might be seen in the offspring of women who drank heavily during pregnancy. "Now a large review has been published ${ }^{6}$ and the syndrome has been defined. ${ }^{7}$ The Fetal Alcohol Study Group of the Research Society on Alcoholism has agreed that for the diagnosis to be made the patient must have signs in each of three categories: growth retardation; lesions in the central nervous system; and at least two of the three characteristic signs of facial dysmorphology. The study group further agreed that a fetus might develop the syndrome if the mother drank more than "five to six drinks on an occasion with at least 45 drinks per month." ("A drink" is about half a pint of beer, a glass of wine, or a single spirit.) Rosett et al have made the next step and shown that if women who do drink heavily reduce their consumption during pregnancy then the outcome is better than in those who do not.

More controversial and difficult to measure is the effect of moderate drinking on reproduction. The Surgeon General in the United States recently advised women not to drink at all during pregnancy," but some see this as extreme advice. The Surgeon General quoted a study that showed significantly decreased birth weight among some women who drink only three standard drinks a day, ${ }^{10}$ and other studies that showed an increase in the rate of spontaneous abortion in women who have as little as two standard drinks a week. ${ }^{11} 12$

Streissguth et al, however, looked at birth weight and motor development at 8 months and related this to maternal alcohol consumption. ${ }^{13}$ They found that the differences in mental and motor scores were little different except at the extremes of consumption-that is, the offspring of mothers who drank heavily had more problems than the offspring of those who drank nothing, but there was little difference between the offspring of those who drank very little or moderately. Thus evidence of harm to babies from moderate maternal alcohol consumption is still only sketchy, and virtually no data are available from Britain. Such data are needed.

\section{Alcohol and the young}

Children in most Western societies, whether damaged by alcohol or not as fetuses, come into contact with alcohol very quickly. In 1972 Jahoda and Cramond showed that most of 240 Glaswegian schoolchildren had formed impressions on alcohol before they started school, and $40^{\circ}$ " of those aged 6 had tried alcohol; most, too, had encountered drunks. ${ }^{14}$ Further studies in Scotland, ${ }^{15}{ }^{16}$ England, $^{17}$ and Canada ${ }^{1 \times}$ showed that, although preadolescent schoolchildren tended to be rather disapproving of alcohol, many teenagers aged 13-17 drank furtively sometimes and most were drinking before they reached the age when legally allowed into pubs. It seems, too, that as with the population generally teenagers are drinking more. ${ }^{18}$

The inevitable corollary is that the young are also experiencing more damage. Drunkenness seems to be increasing: one study in Ontario high schools showed that $42^{\circ}{ }^{\circ}$ of students had been drunk at least once in the previous month and $5.8 \%$ had been drunk 10 times or more. ${ }^{19}$ In Hawker's study of 7306 English adolescents $16 \%$ of boys and $10 \%$ of girls had been "very drunk" in the past year. ${ }^{17}$

A still more recent study by Plant et al ${ }^{20}$ of 1036 Scottish 15 year olds and 16 year olds showed that many were drinking and many were as a result suffering health and social problems: $70 \%$ of the boys and $61 \%$ of the girls had at some time been "merry," "a little bit drunk," or "very drunk"; $40 \%$ " of the boys and $27 \%$ of the girls had had an "upset stomach" from drinking; $6 \%$ of the boys and $6 \%$ of the girls had had a shaky hand the morning after drinking; $18 \%$ of the boys and $20 \%$ of the girls had disagreed with their parents over drinking; $26 \%$ of the boys and $14 \%$ of the girls had "spent too much" on drink; and $3 \%$ of the boys and $2 \%$ of the girls had lost a day's schooling because of drinking. This is a formidable number of consequences from drinking, and it is interesting and disturbing that the differences between boys and girls in both consumption and consequences seem to be narrowing. Although the girls did not consume quite as much as the boys, they suffered almost as many consequences; they also used illicit drugs just as much and even smoked a little more. This is very different from 10 years ago, when girls lagged a long way behind boys in all kinds of drug use. Another disturbing finding was that only $6 \%$ of the boys and $4{ }^{\circ}$ of the girls had ever been worried about their drinking.

Deciding how many young people are alcoholics is as difficult as deciding how many of any population are alcoholics: variable definitions and different survey methods make most of the figures almost pointless. The proportion of young people being admitted to alcohol units is, however, increasing: in $19804 \%$ of those presenting for treatment in Ontario were under 21 as opposed to none in $1964 .{ }^{11}$ But as with adults there is evidence that many of the young who drink heavily and have problems stop drinking as they become older. One American study ${ }^{21}$ showed that whereas $44^{\circ}$ ", of men at college were defined as problem drinkers only $19^{\circ}$ ' were 20 years later. Disturbingly, the prevalence of problem drinking increased among women.

\section{Responding to the alcohol problems of women and the young}

Do "new" groups of the population with alcohol problems need new solutions? As with the population as a whole the response must encompass both treatment and prevention. Studies of special treatment programmes for women are few and far between, but Annis and Liban ${ }^{22}$ have reviewed many of those that exist. Their conclusions were that there was little evidence that women did worse or better than men and that, as with men, the type of patient rather than the type of treatment was the main determinant of outcome. Studies of the outcome of treating young problem drinkers are even rarer, but one from Austria suggested that those under 21 and between 21 and 30 had fewer relapses than those over $30 .^{23}$

Health education may be directed specifically at women and the young, but there is no evidence that any campaigns have been particularly successful. Such campaigns need to be both mounted and vigorously evaluated. Parental influence seems considerably to affect how the young drink, ${ }^{18}$ and health education might be directed at the young via their parents. Political initiatives to respond to the problems might conceivably be directed at particular groups. Licensing laws, for instance, might be used to influence alcohol use among the young. Smart has reviewed evidence showing that areas in North America that have reduced the legal drinking age have experienced more drinking and alcohol-related accicents among the young than those that did not. ${ }^{18}$ But no evidence is available to show that raising the age (obviously a difficult thing in Britain where the age of majority is 18) has any beneficial effect. Alcohol advertising 
to the young in Britain is already curtailed, but little evidence exists to show that this is particularly effective.

The main message that emerges from looking at problems with alcohol among women and the young is that they are not really very different from those among the whole population. More alcohol is being consumed and more problems are resulting in all sections of the population, and strategies for responding to this problem must be much the same for all those sections.

This is the sixth in a series of articles on alcohol.

\section{References}

1 Special Committee of the Royal College of Psychiatrists. Alcohol and alcoholism. London: Tavistock Publications, 1979.

${ }^{2}$ Ferrence RG. Sex differences in the prevalence of problem drinking. In: Kalant OJ, ed. Alcohol and drug problems in women. New York and London: Plenum Press, 1980.

${ }^{3}$ Shaw S. The causes of increasing drinking problems among women. In: Camberwell Council on Alcoholism. Women and alcohol. London: Tavistock Publications, 1980 .

1 Sclare AB. The fetal alcohol syndrome. In: Camberwell Council on Alcoholism. Women and alcohol. London: Tavistock Publications, 1980.

${ }_{5}^{5}$ Lemoine P, Harousseau H, Borteyru JP, Menuet JC. Children of alcoholic parents: anomalies observed in 127 cases. Quest Medical 1968;25: 476-82.

${ }^{6}$ Clarren SK, Smith DW. The fetal alcohol syndrome. $N$ Engl f Med 1978; 298:1063-7.

${ }^{7}$ Rosett HL. A clinical perspective of the fetal alcohol syndrome. Alcoholism: Clinical and Experimental Research 1980;4:119-22.
' Rosett HL, Weiner L, Zuckerman B, McKinlay S, Edelin KC. Reduction of alcohol consumption during pregnancy with benefits to the newborn. Alcoholism: Clinical and Experimental Research 1980;4:178-84.

${ }^{9}$ Anonymous. Surgeon General's advisory on alcohol and pregnancy. FDA Drug Bulletin $1981 ; 11: 9-10$.

10 Little RE. Moderate alcohol use during pregnancy and decreased infant birth rate. Am $\mathcal{F}$ Public Health 1977;67:1154-6.

${ }^{11}$ Kline J, Shrout P, Stein Z, Susser M, Warburton D. Drinking during pregnancy and spontaneous abortion. Lancet 1980;ii:176-80.

1.2 Harlap S, Shiono PH. Alcohol, smoking and incidence of spontaneous abortions in first and second trimester. Lancet 1980;ii:173-6.

${ }^{13}$ Streissguth AP, Barr HM, Martin DC, Herman CS. Effects of maternal alcohol, nicotine and caffeine use during pregnancy on infant neural and motor development at 8 months. Alcoholism: Clinical and Experimental Research 1980;4:152-64.

14 Jahoda G, Cramond J. Children and alcohol. London: HMSO, 1972.

15 Davies J, Stacey B. Teenagers and alcohol. London: HMSO, 1972.

16 Aitken PP. Ten-to-fourteen-year-olds and alcohol. London: HMSO, 1978

${ }^{17}$ Hawker A. Adolescents and alcohol. London: Edsall and Co, 1978.

is Smart RG. The new drinkers: teenage use and abuse of alcohol. Toronto: Addiction Research Foundation, 1980.

19 Smart RG, Gray G, Bennett C. Predictors of drinking and signs of heavy drinking among high school students. International fournal of Studies on Addiction 1978;13:1079-94.

21 Plant MA, Peck DF, Stuart R. Self-reported drinking habits and alcoholrelated consequences among a cohort of Scottish teenagers. Br $\mathcal{F}$ Addic (in press).

21 Fillmore KM. Drinking and problem drinking in early adulthood and middle age: an exploratory 20-ycar follow-up study. Quarterly fournal of Studies on Alcohol $1974 ; 35: 819-40$.

2 Annis HM, Liban CB. Alcoholism in women: treatment modalities and outcomes. In: Kalant OJ. Alcohol and drug problems in women. New York and London: Plenum Press, 1980.

23 Tuchman E. Rehabilitation of alcoholics at Kalksburg (Austria). Br Addict 1965;61:59-70.

\title{
The Six Diseases of WHO
}

\section{Human trypanosomiasis in Africa}

\author{
J R FOULKES
}

The penalties of having vast tracts of land in Africa denied to man and his domestic animals because of the various species of the tsetse fly are incalculable. These flies of the genus Glossina have been described as the "bane of Africa" since the trypanosomes that they host effectively exclude man and his animals from one quarter of the continent. It has been estimated that without Glossina the cattle population could double. Apart from the staggering economic implications to the continent's agriculture the trypanosome also causes human sleeping sickness.

Any general discussion of African trypanosomiasis must start with the realisation that there really are two fairly consistent clinical types of sleeping sickness: West African or Gambian and East African or Rhodesian. The West African disease is largely transmitted by tsetse flies of the Glossina palpalis group that feed along the rivers and harbour Trypanosoma (Trypanozoon) gambiense. The East African disease is largely transmitted by tsetse flies of the $G$ morsitans group that inhabit the savannah country and host $T(T)$ rhodesiense. Table I outlines some of the major differences between the two forms and illustrates the fallacy of thinking about African trypanosomiasis as a single

The Mukinge Hospital, Kasempa, Zambia

J R FOULKES, MD, medical officer
TABLE I-Differences between Gambian and Rhodesian disease

\begin{tabular}{|c|c|}
\hline $\begin{array}{c}\text { Gambian } \\
\text { (West African, } T(T) \text { gambiense) }\end{array}$ & $\begin{array}{c}\text { Rhodesian } \\
\text { (East African, } T(T) \text { rhodesiense) }\end{array}$ \\
\hline $\begin{array}{l}\text { Chronic-university student in England } \\
\text { who developed symptoms two years } \\
\text { after leaving Ghana }\end{array}$ & $\begin{array}{l}\text { Acute-progresses rapidly to death } \\
\text { within a few months-almost } \\
\text { universally fatal if untreated }\end{array}$ \\
\hline Man-fly-man cycle & $\begin{array}{l}\text { Wild game-fly-wild game cycle with } \\
\text { man only a temporary interloper }\end{array}$ \\
\hline $\begin{array}{l}\text { Healthy carriers common } \\
\text { Transmitted largely by } G \text { palpalis group } \\
\text { of riverine tsetse flies }\end{array}$ & $\begin{array}{l}\text { Healthy carriers uncommon } \\
\text { Transmitted largely by } G \text { morsitans } \\
\text { group of savannah tsetse flies }\end{array}$ \\
\hline $\begin{array}{l}\text { Infected fies are close to villages-many } \\
\text { women and children infected }\end{array}$ & $\begin{array}{l}\text { Occupational hazard to hunters and } \\
\text { fishermen. Very few women and } \\
\text { children infected (except in an } \\
\text { epidemic) }\end{array}$ \\
\hline $\begin{array}{l}\text { Lymphadenopathy a prominent feature, } \\
\text { and node aspiration highly productive } \\
\text { in making the diagnosis }\end{array}$ & $\begin{array}{l}\text { Lymphadenopathy much less prominent } \\
\text { and node aspiration less productive } \\
\text { than blood slide in making diagnosis }\end{array}$ \\
\hline Prophylactic injections valuable & $\begin{array}{l}\text { Prophylactic injections completely } \\
\text { unreliable }\end{array}$ \\
\hline
\end{tabular}

entity. The sharp lines of distinction in the chart are only generally true, and there are many exceptions. For instance, there is a geographical overlapping of the two forms of the disease on the shores of Lake Victoria, and cases of Rhodesian sleeping sickness have on occasion been transmitted by $G$ palpalis. Even the separation between the species of the trypanosome is debatable, and some workers, such as Ormerod, ${ }^{1}$ conclude that $T(T)$ gambiense, $T(T)$ rhodesiense, and even $T(T)$ 